\author{
구조의 절점 형식에 따른 형상 형성의 거동 특성 \\ 김진우* • 엄장섭** • 이용희*** \\ *경상대학교 해양과학대학 해양토목공학과(해양산업연구소) \\ **창신대학교 토목공학과 \\ ***가야대학교 도시토목환경학과
}

\title{
Behavior Characteristic of Shaping Formation according to Joint Type of Structures
}

\author{
Jin-Woo Kim*, Jang-Sub Eom** and Yong-Hee Lee*** \\ *Department of Ocean Civil Engineering (Institude of Marine Industry), Gyeongsang National University, Tongyeong, Korea \\ **Department of Civil Engineering, Changshin University, Changwon, Korea \\ ***Department of Urban, Civil Engineering Environment, Kaya University, Gimhae, Korea
}

KEY WORDS: Cable-tensioning 케이블텐션닝, Joint type 조인트형식, Mechanism 메커니즘, SCST structure SCST구조

\begin{abstract}
This paper concerned with the behaviour of shaping formation and the erection for SCST structure by cable-tensioning for three kinds of structure models. The joint types of experimental models are ball type joints, bolt type joints with gusset plates, and bolt type joints. The feasibility of the proposed shaping method and the reliability of the established geometric model were confirmed with a nonlinear finite element analysis and an experimental investigation for full size scaled pyramid test model and three kinds of SCST structure models. The characteristic of the behaviour of each joint type is shown in the shaping test for practical design purposes. As a results, the behaviour characteristics of joints is very significant in shaping analysis of space structures. So the joint type should be considered in the design and analysis of the shape formation for space structures. Also, in the special field condition, it could be a fast and economical method for constructing the space structure.
\end{abstract}

\section{1. 서 론}

최근 들어 고강도의 강재가 개발되고 구조 해석의 기법과 시 공 기술이 발달됨에 따라서 대경간 구조물의 건설에는 공간 구 조의 형식이 많이 도입되고 있다. 재료가 절약되고 미려하며 시 공 속도가 빠른 장점을 가진 공간 구조는 각종 공연 시설, 위락 시 설, 상업 시설, 체육 시설 등과 같은 구조 형식에 널리 이용되고 있다. 특히 경간을 길게 하거나 하중 저항 능력을 향상시키는 경 제적인 방법으로 알려진 프리스트레스를 이용한 SES (Self-erected structure)의 기법이 많은 구조물에 도입되고 있다(Punniyakotty et al., 2000). 현재 이용되고 있는 공간 구조의 주요 요소 들은 일정 기준의 품질 관리에 의해 공장에서 대량으로 생산되 고 있으므로 현장에서 제작되는 구조 요소보다 신뢰성이 높다. 그리고 경량 구조이기 때문에 운반이 용이하고, 현장 조립의 형 태가 많아서 공기를 단축할 수 있으며, 공간 구조의 특성상 하 중이 3차원적으로 균등하게 분배되기 때문에 각 부재는 충분한 강성을 가지고 하중을 부담할 수 있다. 이와 같은 특성이 있기 때문에 공간 구조는 구조 형식별로 각각의 용도에 적합한 절점 (조인트)이 개발되어 상용화 되고 있는데, 절점은 해석이 복잡
하고 다른 구조 요소에 비해 제작이 어렵기 때문에 전체 구조 물의 건설비용을 좌우하는 중요한 요소가 된다. 공간구조에 이 용되는 조인트는 그 종류가 많을 뿐 아니라 거동 특성이 매우 복잡하기 때문에 이런 특징에 대해서는 많은 연구가 수행되어 왔다. 또 조인트의 강도나 휨강성은 구조물의 파괴에 직접적인 영향을 미치며 하중이 재하 되는 경우 대부분의 파괴도 이 절 점부분에서 발생된다(El-Sheikh, 1993; Feng, 2010). 그리고 구조 의 기하학적인 형태나 부재의 세장비, 하중이력 등도 구조 거동에 많은 영향을 미치는 것으로 알려져 있다(Aitziber, 2007). 공간 구조의 설계에서 절점은 가장 중요한 요소이므로 견고하고 적 당한 강성을 가져야 하며, 효율적인 시공이나 유지 관리를 위해 서 제작이 쉬워야 하고 고도의 가공을 요구하지 않아야 경제성 이 있다. 특히 여러 부재가 하나의 절점에 연결될 때 편심이 발 생하게 되면 2차 응력이 발생되기 때문에 제작의 정도가 유지 되거나 편심 오차를 흡수할 수 있는 구조가 되어야 한다.

본 연구에서 이용되고 있는 프리스트레스 공법은 주로 콘크 리트 구조물에 적용되어 왔으나, 1980년대부터 공간 트러스 구 조의 형상 형성에 이 공법이 도입되어 그 거동 특성을 파악하 는 많은 연구가 수행되어 왔다(김진우, 1998, 2000, 2001, 2002;

교신저자 김진우: 경남 통영시 인평동 445, 055-772-9125, kim@gnu.ac.kr 
김진우 등, 2005; Dehdashti et al., 1996; Hoe et al., 1986; Kim et al., 2000, 2001, 2002, 2003, 2004, 2005, 2006, 2007; Koushky et al., 2007; Ram, 1991; Schmidt et al., 1999). 이 공법의 특징 은 대형 크레인이나 동바리를 이용하지 않고 지상에서 공간 구 조를 조립하여 Cable-tensioning에 의해 최종 구조를 시공하는 $\mathrm{SES}$ 방식이다. 이는 동바리나 비계의 설치가 곤란한 작업 현장 이나 대형 크레인을 동원하기 어려운 도서 벽지와 같은 시공 현장 에서는 새로운 대안 공법이 될 수 있을 것이라 생각된다. 그리 고 이 공법에 의하면 작업원이 고소 작업을 하지 않아도 되기 때문에 작업원의 안전이 확보되고품질 관리가 용이하므로 충분 히 경쟁력이 있는 공법이 될 수 있다.

일반적으로 강구조 방식의 공간구조의 형상 형성에는 SCST( Single-chorded-space-truss) 구조가 이용된다. 이 구조는 구조물의 자중이나 절점의 마찰, 상현재의 휨강도 등으로 변형에 저항하 기 때문에 Cable-tensioning에 의한 작은 하중의 재하만으로도 형상 형성이 가능한 특징을 가지고 있다. 이는 초기에 하현재에 존재해 있는 갭(Gap)의 크기를 줄이는 Cable-tensioning에 의해 서 안정된 구조가 되어 사용 하중에 저항할 수 있게 되며, 이 구 조는 단층(Single-layer) 공간 구조와 복층(Double-layer) 공간 구 조의 중간 형식이라 할 수 있다.

본 연구에서는 저자의 선행 연구에서 피라미드 구조와 보구조 의 하중-변위 관계의 거동 특성을 분석한 결과, 발생되는 변형 은 부재의 탄성 한도 내의 작은 하중에 의한 변형이므로 이는 절점의 변형에 의해서 발생된다는 결과에 근거하여, 절점의 형 태가 각각 다른 3 종류의 공간 구조 모델에 대한 형상 형성 시험 및 비선형 유한요소해석의 결과를 분석하여 그 거동 특성을 규 명하였다. 시험에 이용된 공간 구조 모델은 실물크기의 피라미 드형 기본 구조와 구형 절점으로 제작된 모델 $\mathrm{A}$, 보강판(Gusset plate)을 덧대어 볼트로 절점을 제작한 모델 $\mathrm{B}$, 그리고 볼트만으 로 절점을 제작한 모델 $\mathrm{C}$ 이다.

\section{2. 형상 형성의 개념과 메커니즘}

Cable-tensioning에 의한 공간구조의 형상 형성은 Fig. 1과 같

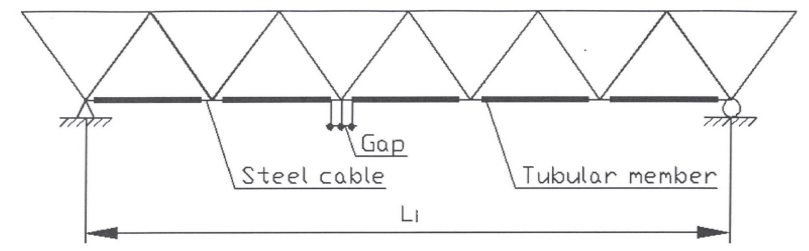

(a)

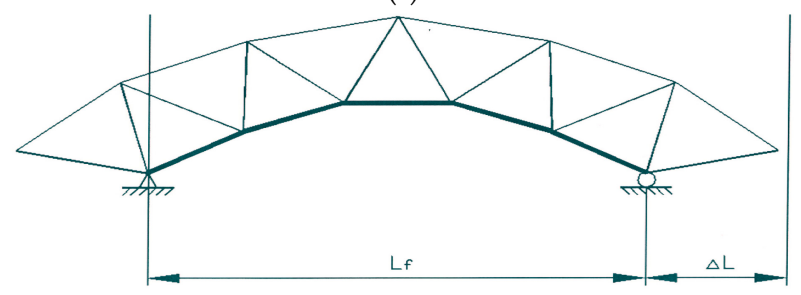

(b)

Fig. 1 The concept of cable-tensioning method in SCST structure
은 개념으로 이루어진다. 하현재 내부의 강선에 Cable-tensioning을 가하면 Fig. 1의 (a)와 같이 초기에 존재하던 갭이 점차 없어지면서 0 (zero)에 이르게 되고, 이때 하현재의 전체 길이는 $L_{i}$ 에서 $L_{f}$ 로 변화하여 공간 구조의 형상 형성이 이루어지게 된 다. 즉 Fig. 1에서 (a)는 Cable-tensioning을 가하기 전의 지상에 배치된 평면 상태의 구조이며 (b)는 하현재에 Cable-tensioning 을 가하여 최종적인 공간 구조를 형성한 것이다. 그리고 Maxwell Criterion으로 알려진 메커니즘 조건에 의해서(Calladine, 1978), Cable-tensioning에 의해 형성된 SCST형의 공간 구조는 Cable-tensioning을 가하기 전에는 메커니즘이 존재해야 한다. 메커니즘 조건이란 '구조물의 초기 형상에만 메커니즘 또는 유 사 메커니즘이 존재해야 하며 최종 형상에는 어떤 메커니즘도 존재하지 않아야 한다' 는 것이다. 이 조건은 구조물이 그 초기 형태에 비교적 작은 Cable-tensioning을 가해서 구조 형성이 가 능 하도록 필요한 조건일 뿐만 아니라 형성된 공간 구조의 구 조 안정에도 필요하다.

\section{3. 비선형 유한 요소 해석}

구조물의 형상 형성에는 컴퓨터를 이용한 수치 해석의 기법이 널리 이용되고 있는데, 주로 구조물의 경간, 높이, 하중 재하의 조건, 요구되는 응력 조건 등을 부여해서 구조 형상을 해석할 수 있는 연구가 수행되어 왔다. 이들은 컴퓨터 해석에 기반하여 강선에 프리스트레스를 가해서 형상 형성을 하는 일반적인 연 구 방법이며 이는 SES 방식의 기본이 되는 기법이다.

구조 거동의 비선형성은 재료의 비선형성과 구조계의 기하학 적 비선형성으로 구분된다. 구조물의 거동이 큰 변형을 유발하 거나 변형률의 변화가 큰 구조물, 사용 재료의 응력과 변형률의 관계가 비선형인 구조물 등은 각각의 경우에 적합하도록 기하 학적 비선형 해석이나 재료의 비선형 해석을 해야 한다. 본 연 구의 시험모델은 구조계의 큰 변형의 영향을 고려해야 하므로 기하학적 비선형 해석을 하였다. 일반적으로 Single-layer shells 등과 같은 공간 구조의 거동은 기하 비선형성이 매우 강한 반 면 재료 비선형성은 약하고, Double-layer shells 등은 재료 비 선형성이나 기하 비선형성의 정도가 중간 정도이며, Doublelayer grids 등은 재료 비선형성이 강하지만 기하 비선형성은 약한 것으로 알려져 있다. 또 장경간의 격자 구조 등은 기하 비 선형의 영향이 재료 비선형의 영향보다 더 강한 것으로 알려져 있고, 경간이 작으면 이와는 반대로 생각할 수 있으며, 중간 정 도의 경간이면 재료 및 기하 비선형 모두를 고려해야 한다 (Erling, 1984).

본 연구자를 포함한 많은 선행 연구자들의 연구 결과에 의하 면 포스트텐션으로 공간 구조의 형상 형성을 하는 경우에 구조 물의 거동은 비선형 거동을 하는 것으로 알려져 있으며, 그 거 동의 특성도 구조 형태에 따라 다양한 경향을 보이고 있다. 그 리고 비선형 해석 기법이 다양하지만 구형 절점의 일종인 $\mathrm{MERO}$ 시스템으로 이루어진 공간 구조의 형상 형성 해석에는 Total lagrangian approach (TL)기법이나 Updated lagrangian approach (UL)기법 모두가 비슷한 결과를 나타냄을 제시하였으 
며, 이 경우에 부재를 Truss 요소 및 Beam 요소로 각각 모델링한 경우의 해석 결과는 거의 일치함도 확인하였다(김진우 등, 2005). 따라서 본 연구에서 이용된 시험 모델의 모든 부재는 일반적인 트러스 해석에 적용되는 Truss요소로 모델링하여 하현재에 음 의 온도하중을 가하여 수축변형을 하게 하는 방법으로 해석하 였는데 온도하중은 구조형상을 결정짓는 Gap의 크기에 따라 결정된다. 구조해석은 토목, 건축분야에 널리 사용되고 있는 상 용 프로그램인 MIDAS를 이용하여 형상 형성 해석을 하였다.

\section{4. 실물 크기의 피라미드형 기본 구조 시험}

본 연구에서는 공간 구조의 형상 형성시의 거동 특성을 규명 하기 위해 Fig. 2와 같은 피라미드형 단위 구조에 대해 하중-변 위 시험을 수행하여 구형 절점 거동 특성을 고찰하였고, 이 절점 의 거동이 공간 구조의 형상 형성에 미치는 영향에 대해 분석 하였다.

Strong floor에 설치된 기본 구조에서 절점 $\mathrm{A}$ 는 수평 및 수직 방향이 모두 구속되어 있으며, 절점 $\mathrm{B}$ 와 $\mathrm{D}$ 는 수평 방향이나 수 직 방향 모두 이동이 가능한 구조이다. 그리고 절점 $\mathrm{C}$ 는 수직 방향으로만 구속되어 있고 $\mathrm{AC}$ 방향의 수평 방향으로만 이동이 가능하다. 부재는 구형 절점으로 $76 \times 5.5 \mathrm{~mm}$ 의 원형 중공 단면 부재가 연결되어 있고 길이는 $2,250 \mathrm{~mm}$ 이며, 탄성계수는 200 $\mathrm{GPa}$, 포아슨의 비는 0.3 , 항복강도는 $350 \mathrm{MPa}$ 이다. 유압잭을 이 용하여 절점 $\mathrm{C}$ 에서 절점 $\mathrm{A}$ 를 향해서 수평 방향으로 하중을 재 하 하였으며, 이 때 각 절점의 이동량인 $\mathrm{AC}$ 및 $\mathrm{BD}$ 의 길이의 변 화량을 측정하였다.

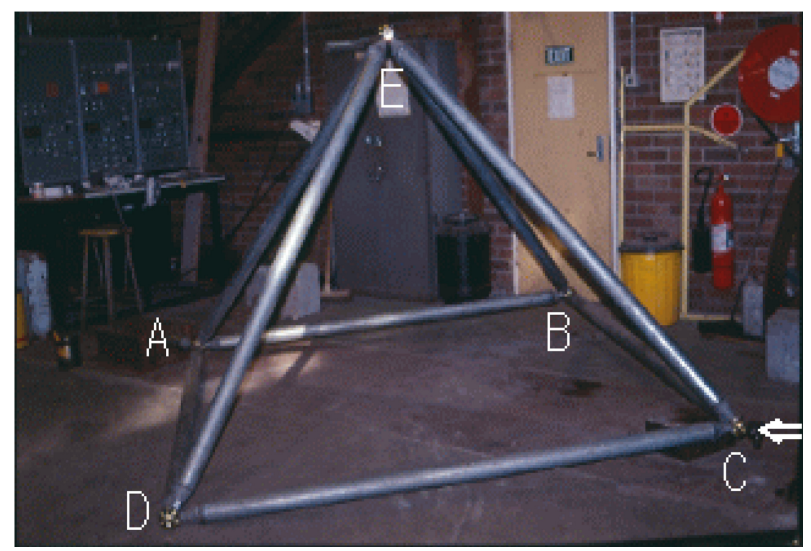

Fig. 2 Test of pyramid unit structure

\section{5. 시험 모델에 대한 형상 형성 시험}

피라미드형 구조의 하중-변위 시험의 결과를 실제 공간 구조 에 적용하여 형상 형성에 미치는 영향을 분석하기 위하여 Fig. 3 과 같은 3종류의 절점으로 제작된 시험모델별로 Fig. 4의 (a)와 같은 아치형(모델 A), Fig. 4의 (b)와 같이 제작한 돔형(모델 B), 그리고 Fig. 4의 (c)와 같이 제작된 하이파형(모델 C)의 공간 구 조에 대해 형상 형성 시험을 수행하였다. 제작된 시험 모델은 Cable-tensioning에 의한 공간 구조의 형상 형성에서 요구되는

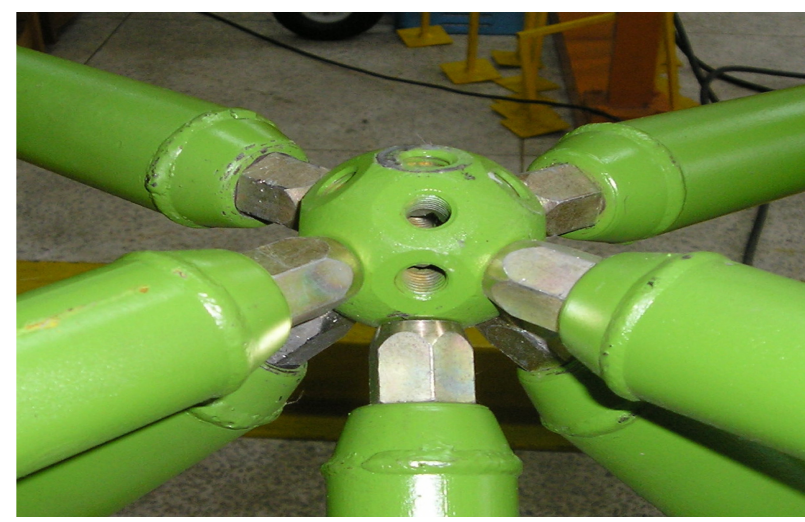

(a) Ball type joint for model A

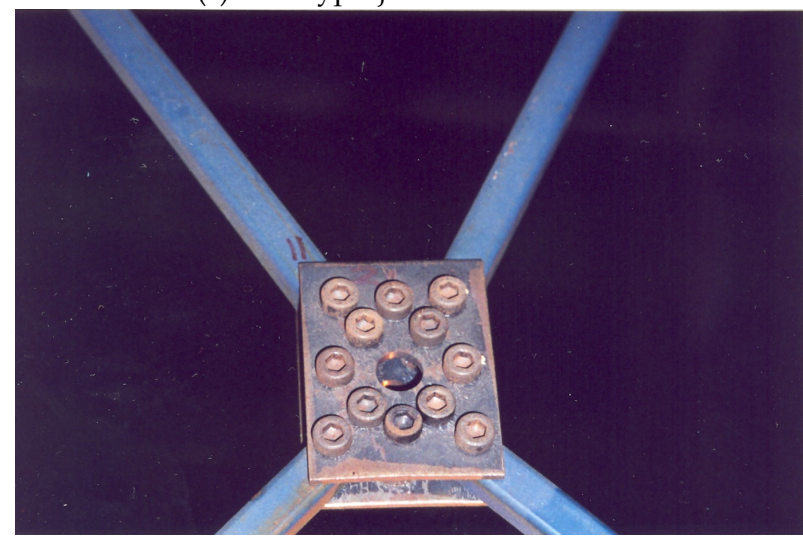

(b) Bolt type joint stiffened with gusset plate for model B

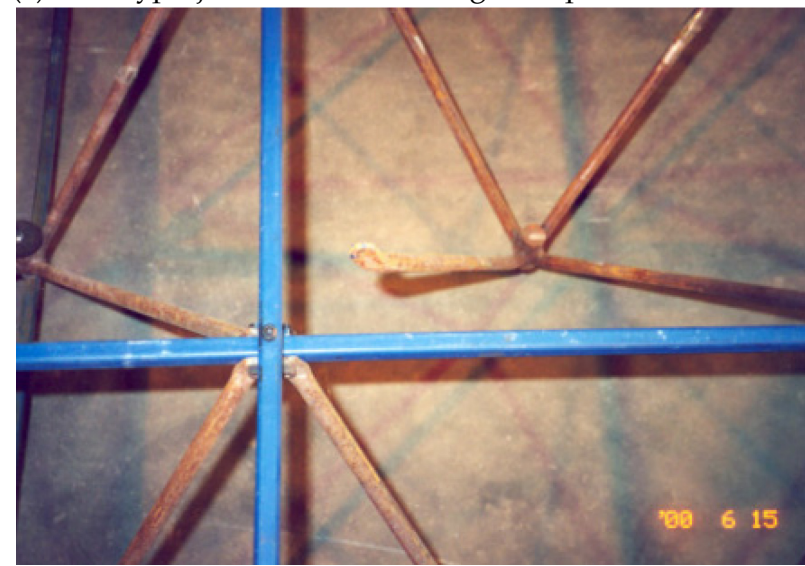

(c) Bolt type joint for model C

Fig. 3 Three kinds of joint type in SCST structures

메커니즘 조건과 기하학적인 적합 조건을 만족하고 있다.

Cable-tensioning에 의한 형상 형성의 기본 요건은 비교적 작 은 하중으로 형상의 형성이 가능해야 하는데, 본 실험에 이용된 SCST 구조는 이의 조건에 적합한 구조 형식이다. Fig. 4 에서 굵 은 실선으로 나타낸 것은 갭의 크기를 조절하는 기능을 가진 부재이며, Cable-tensioning을 가하기 위한 강선이 그 내부에 배 치되어 있고, 이에는 프리스트레스를 가하기 전에 형상 형성에 필요한 양만큼의 갭(Gap)이 존재한다. 하현재의 절점에는 하현 재를 따라 강선을 배치시킬 수 있도록 하기 위하여 Cabletensioning 가이드를 부착하였으며, Cable-tensioning 을 가한 후에 강선을 정착시킬 수 있도록 강선의 양단 절점에 정착단을 


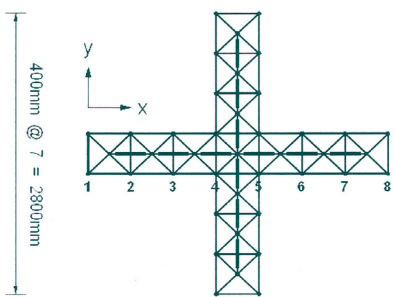

$400 \mathrm{~mm} @ 7=2800 \mathrm{~mm}$

(a) Model A

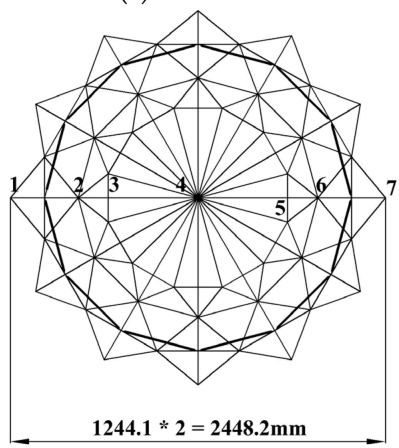

(b) Model B

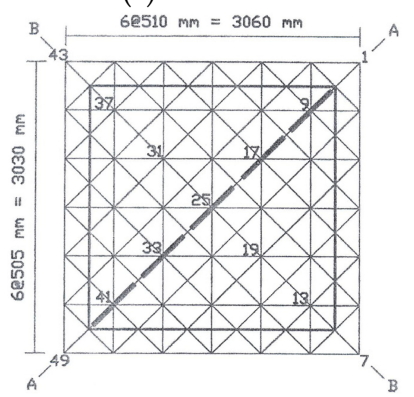

(c) Model C

Fig. 4 Planar layouts of three kinds of test models

배치하였다. 강관 내부에 배치된 강선에 모노잭으로 인장력을 가하여 공간 구조가 형성되게 하였으며, 이 때 존재하는 갭이 완전하게 없어졌을 때 Cable-tensioning 작업이 완료되었다. Cabletensioning을 가하는 동안 전체 구조는 양단부의 갭이 먼저 좁 아지고 이어서 중앙부의 갭이 점차 좁아지는 현상을 보였다. 최 종적인 공간 구조가 형성되면 유한 요소 해석에 의한 값과 비 교하기 위해서 상현재의 조인트의 수직 변위를 레벨로 측정하 였다.

Fig. 4의 시험 모델들은 피라미드형의 기본 구조 단위의 조합 으로 이루어져 있는데, 시험모델A에서 이용된 부재는 원형 중 공관으로 제작되어 있는데 탄성 계수는 $136 \mathrm{GPa}$ 이며 포아슨의 비는 0.3 이고 항복 강도는 $334 \mathrm{MPa}$ 이다. Fig. 4 의 (b)와 같은 시 험 모델 $\mathrm{B}$ 는 사용하는 용도에 따라 크기를 확장할 수 있는 디 플로이어블(Deployable) 구조로 제작되어 있다. 강선은 원주 방 향을 따라서 Cable-tensioning을 가할 수 있도록 배치되어 있다. 각 부재는 상현재가 SHS $13 \times 13 \times 1.5 \mathrm{~mm}$ 인 중공 사각형 단면, 웨 브는 CHS $13 \times 2.5 \mathrm{~mm}$ 의 중공 원형 단면, 그리고 하현재에서 갭 을 조절하는 부재는 웨브 부재와 규격이 같다. 포아슨의 비는 0.3 이며 항복강도는 상현재가 $450 \mathrm{MPa}$, 웨브 부재가 $440 \mathrm{MPa}$,
그리고 하현재는 $440 \mathrm{MPa}$ 이고 탄성계수는 200GPa이다. Fig. 4 의 (c)와 같은 시험 모델 C는 상현재가 SHS $13 \times 13 \times 1.8 \mathrm{~mm}$ 인 중 공 사각형 단면, 웨브는 CHS $13 \times 2.0 \mathrm{~mm}$ 의 중공 원형 단면, 그 리고 하현재는 CHS $27 \times 8.75 \mathrm{~mm}$ 의 중공 원형 단면으로 구성되 어 있다. 포아슨의 비는 0.3 이며 항복 강도는 $350 \mathrm{MPa}$, 탄성계수 는 200GPa이다.

\section{6. 결과 및 고찰}

저자는 선행 연구에서 SCST 구조 형식의 공간 구조에 대한 모델 시험을 실시하고 그 모델에 대한 유한 요소 해석을 통해서 다양한 형태의 공간 구조에 대한 거동 특성의 결과를 밝힌 바 가 있다. 그러나 이들은 모두 부재의 항복강도 이내의 아주 작은 하중으로 형상 형성이 가능하였으므로 이런 거동은 절점의 거 동에 관련된다는 것에 착안하여 절점의 거동 특성을 분석하였 다. 이를 위해 공간 구조의 기본 요소가 되는 피라미드형의 단위 구조에 대한 하중-변위의 시험을 수행하고, 그 결과는 Fig. 5와 같이 각 하중 단계에 따라 $\mathrm{BD}$ 길이의 신장량과 $\mathrm{AC}$ 길이의 수 축량을 나타내었다. 그림에 나타낸 바와 같이 비교적 작은 하중 임에도 불구하고 구조는 큰 변형을 보였는데 이는 구조가 메커 니즘 상태에 있기 때문이다. 그리고 하중-변위의 선도는 모두 비선형 거동의 특성을 보이고 있는데, $\mathrm{BD}$ 길이와 $\mathrm{AC}$ 길이의 변 화는 거의 유사한 경향을 보이고 있으며, 하중을 제거한 이후에 도 약간의 영구 변형을 나타내고 있다. 따라서 피라미드형의 단 위 구조에 재하된 하중은 각 부재의 탄성의 범위 내에 있는 작은 하중값이기 때문에 부재의 변형은 없으므로 피라미드형 단위 구조의 변형은 구형 절점의 회전 변위에 의해 발생된 것이라 생각할 수 있다. 또 하중-변위 시험 후에 피라미드형의 구조를 분해하여 구형 절점과 부재의 연결부 등의 변형을 관찰한 결과 재하된 하중이 작았기 때문에 어떤 변형도 발생되지 않았음을 확인할 수 있었다. 그러므로 여기서 발생된 영구 변형은 저자의 선행 연구에서 밝힌 바와 같은 탄성 범위 이내의 하중에 의한 절점의 변형임을 알 수 있다(Kim, et al., 2002).

Fig. 6은 각 절점 형식별로 제작된 구조 모델에 대하여 Cabletensioning을 가해서 형성된 최종적인 공간 구조를 나타낸 것인

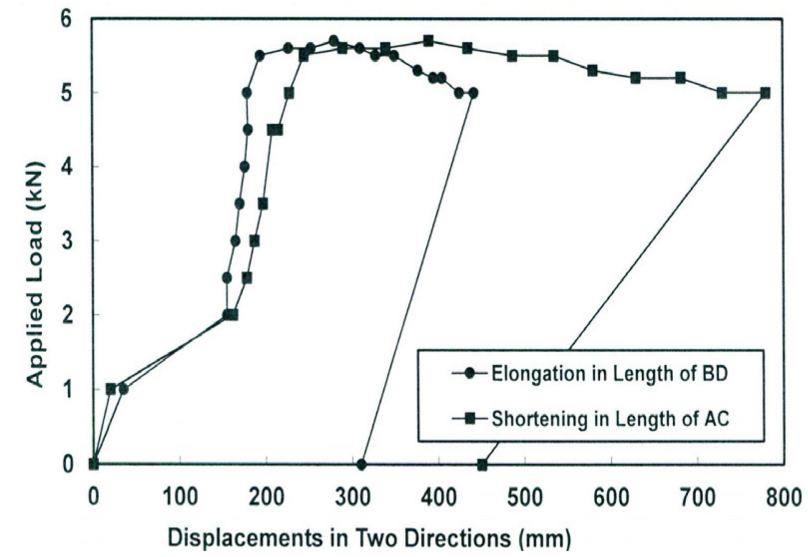

Fig. 5 Relationship of load-displacement in pyramid unit 


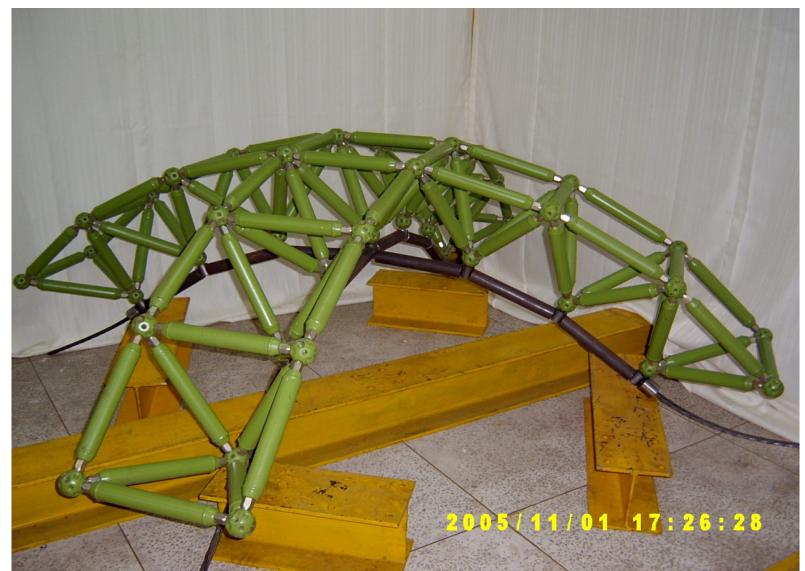

(a) Model A

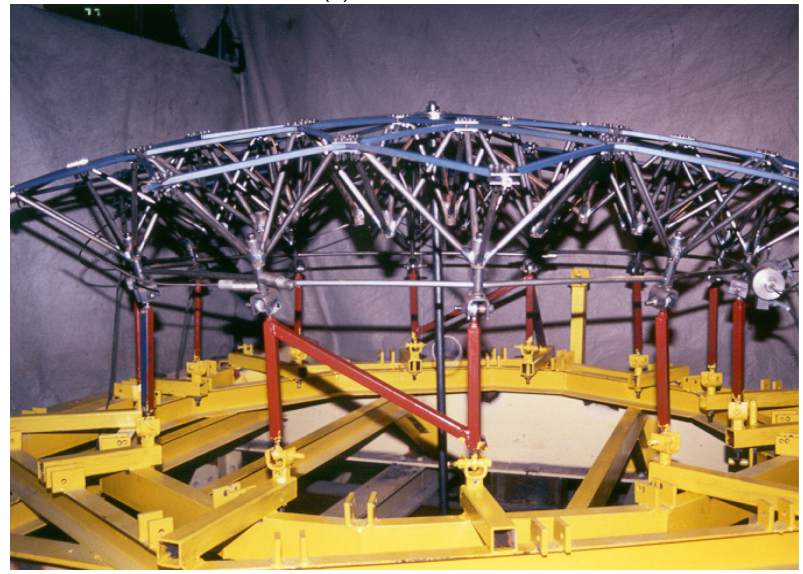

(b) Model B

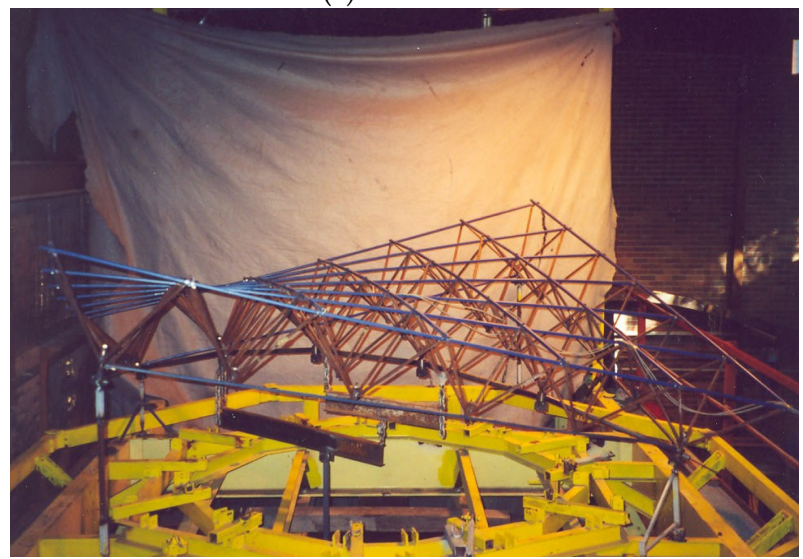

(c) Model C

Fig. 6 Shape formation in three type of space structures

데 이는 SCST 구조에 Cable-tensioning을 가한 구조이므로 텐션 에 의해 유발된 각 부재의 부재력은 아주 작다. 이와 같이 형성 된 구조 모델들에 대한 형상 형성 시험의 결과를 Fig. 7에 나타 내었는데 기하학적 비선형성을 고려한 해석에 의한 값이 실측 치와 근사한 경향을 보임을 확인할 수 있었다. 그러나 각 절점 의 형식별로 형상 형성의 구조 거동이 다소 다른 경향을 보이고 있는데 이것은 절점의 거동 특성이 공간 구조의 형상 형성에 큰 영향을 미치는 것이라 사료된다. 모델 $\mathrm{A}$ 와 모델 $\mathrm{B}$ 는 절점의 형식이 다르므로 실측치와 이론치가 약간의 차이를 두고 일치

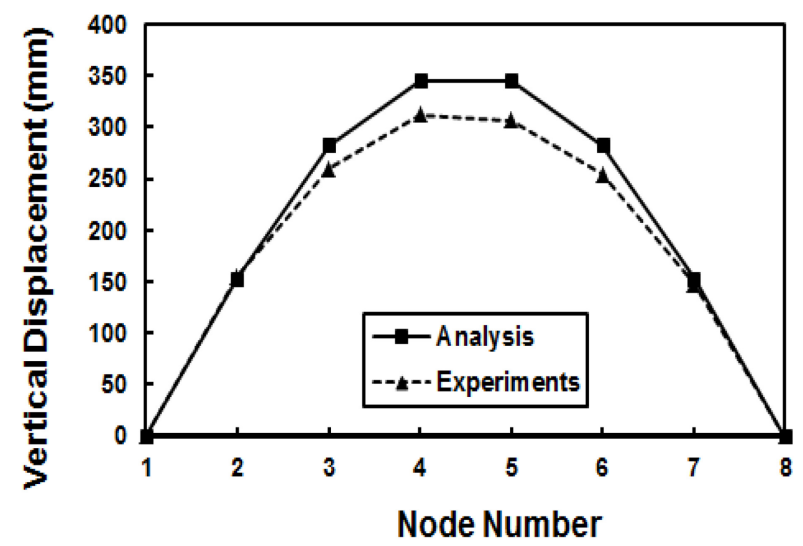

(a) Model A

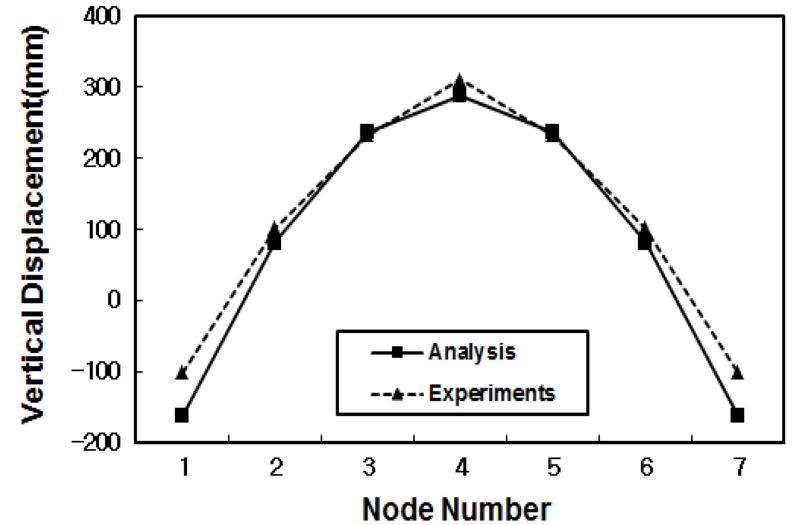

(b) Model B

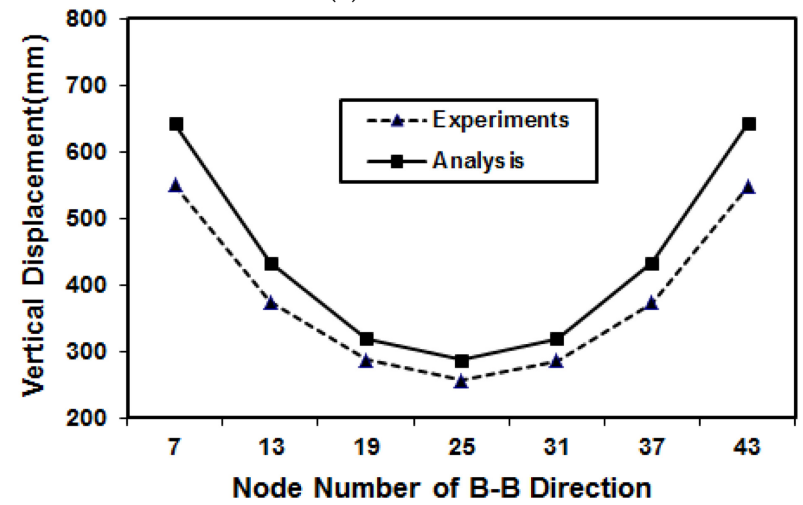

(C) Model C

Fig. 7 Analysis and shape formation of test models

함을 보이고 있으며, 특히 모델 $\mathrm{C}$ 의 경우는 실험의 결과와 해석 의 결과가 모델 $\mathrm{A}$ 나 $\mathrm{B}$ 에 비해 일정한 간격을 유지하면서 일치 도가 낮은 것을 볼 수 있는데 이것은 저자의 선행 연구(Kim et al., 2006)에서 밝혀진 바와 같이 하이파 구조의 특성에 의한 현 상이나, 절점의 구조 특성의 차이에서 발생되는 것으로 생각된다. 또 이 경우에 특정 부재를 제거하여 형상 형성 시험을 했을 때 각기 다른 거동 특성을 보였던 것은 기하학적인 형상의 차이에 기인하는 것으로 판단된다. 그리고 본 연구를 통하여 Cabletensioning에 의해 형상이 형성되는 공간 구조의 모델 시험에서 형상 형성과 Self-erection 과정이 동시에 일어나는 SES의 가능 성을 확인할 수 있었는데 이것은 도서 벽지와 같은 대형 크레 
인을 동원할 수 없는 특수한 시공 현장에서 Cable-tensioning에 의하여 공간구조를 시공할 때 적절한 공법이 될 수 있음을 나 타낸다. 본 모델의 시험을 위한 기본 시험인 피라미드형 구조에 서도 밝혀진 절점의 비선형 거동 특성을 고려하고, 각 모델을 구성하는 부재의 항복강도 이하인 비교적 작은 하중으로 형상 형성이 완료되는 비선형 거동의 특성도 부재의 변형이 아니라 각 형식별 절점의 회전 변형에 의한 비선형 거동의 결과임을 알 수 있다. 결국 형상 형성을 위한 하중은 부재의 항복강도보 다 훨씬 작은 하중을 가해 형성되므로 전체 구조의 변형은 절점 (조인트)의 변형으로 발생된다고 결론 지을 수 있다. 따라서 형 상 형성시의 거동은 절점의 거동 특성에 유의해야 하며, 트러스 부 재로 모델링한 비선형 유한 요소 해석으로 공간 구조의 형상 형 성을 하면 구조물의 최종 형상을 예측할 수 있다. 또 유한 요소 해석에서 얻어지는 각각의 부재력과 응력을 분석함으로써 원하 는 구조 형상의 형성에 필요한 Cable-tensioning의 크기를 추정할 수 있으며, 이 결과는 시공 장비의 규모 산정에도 적절하게 이 용될 수 있다. 그러나 형상 형성 후에 일부의 한계 부재(Critical member)에 프리스트레스가 존재할 경우에는 형성된 구조의 극 한 하중 능력이 저하되는 경우가 있을 수 있으므로 이런 경우 는 해석을 통해서 이를 확인하여 필요할 경우 해당 부재에 대 한 보강 조치가 요구된다.

\section{7. 결 론}

실물 크기인 피라미드형의 기본 구조에 대한 하중-변위 시험 을 수행하고, 각각 다른 3종류의 절점으로 제작된 공간 구조 모델 에 대해서 형상 형성 시험 및 비선형 유한요소 해석을 수행한 결 과 다음과 같은 결론을 얻을 수 있었다.

(1) 실물 크기의 피라미드형 기본 구조의 변형은 절점의 회전 변 형에 의한 것이며 이 변형은 비선형 거동의 특성을 보이고 있다.

(2) 피라미드형 기본 구조를 이용한 SCST 구조는 절점의 형식 에 따라 형상 형성의 거동이 각각 다른 특성을 보이고 있으므로 설계시 절점의 유형을 고려해야 한다.

(3) Cable-tensioning에 의해 형성된 공간 구조의 형상 형성 해 석에서 비선형 해석에 의한 값은 실측치에 비교적 가까운 값이다.

(4) Cable-tensioning 공법에 의한 공간 구조의 형상 형성은 비 계나 대형 크레인이 필요하지 않으므로 현장의 특수한 시공 조 건에 따라서 적절하게 이용하면 경제적인 공법이 될 수 있다.

\section{후 기}

이 연구는 2010년도 경상대학교 학술진흥지원사업 연구비에 의하여 수행되었음(RPP-2010-000)

\section{참 고 문 헌}

김진우 (1998). “돔형 공간트러스의 비선형 거동”, 한국해양공학 회 논문집, $\mathrm{Vol} 12$, No 4, pp 1-7.
김진우 (2000). "돔형 공간트러스의 해석과 실험", 대한토목학회 논문집, 20 (1-A), pp 39-46.

김진우 (2001), "포스트텐션에 의한 공간 트러스의 형성과 극한 하중시험", 대한건축학회논문집(구조계), Vol 17, No 5, pp 51-57.

김진우 (2002). “포스트텐션에 의한 격자 돔형 공간구조의 특 성", 한국해양공학회 논문집, $\mathrm{Vol} 16$, No 1, pp 41-45.

김진우, 권민호, 유해준(2005). “다방향성 연결구로 구성된 아치 형 공간구조의 형상 형성과 비선형 해석", 대한건축학회논 문집(구조계), 21 (11), pp 11-18.

Aitziber Lopez (2007). “Numerical Model and Experimental Tests on Single-layer Latticed Domes with Semi-rigid Joints", Computers and Structures, Vol 85, pp 360-374.

Calladine, C.R. (1978). “Buckminster Fuller's Tensegrity Structures and Clerk Maxwell's Rule for the Construction of Stiff Frames", Int. J. Solids Struc., Vol 14, No 3, pp 161-172.

Dehdashti, G. and Schmidt, L.C. (1996). “Dome-shaped Space Trusses Formed by Means of Post Tensioning", J. of Str. Eng., ASCE, Vol 122, No 10, pp 1240-1245.

El-Sheikh (1993). "Numerical Analysis of Space Trusses with Flexible Member-end Joints", International Journal of Space Structures, Vol 8, No 3, pp 189-197.

Erling A. Smith (1984). "Space Truss Nonlinear Analysis", J. Struc. Engra., ASCE, Vol 110, No 4, pp 688-705.

Feng Fan, Hui-huan. Ma, Zheng-gang Cao and Shi-zhao Shen (2010). "Direct Estimation of Critical Load for SingleLayer Recticulated Domes with Semi-Rigid Joints", International Journal of Space Structures. Vol 25, No 1, pp 15-24.

Hoe, T.T. and Schmidt, L.C. (1986). "Ultimate Load Behaviour of Barrel Vault Space Truss", Int. J. of Space Structures, Vol 2, pp 1-10.

Kim, J.W., Kim, J.J. and Rhew, H.J. (2005). "Analysis and Experiment for the Formation and Ultimate Load Testing of a Hyper Space Truss", J. of Constructional Steel Research, Vol 92, pp 189-193.

Kim, J.W., Kwon, M.H. and Lee, Y.H. (2006). "Influence of Removed Members in Shaping Formation for Hypar Space Truss", The Korean Society of Ocean Engineering, Vol 20, No 2, pp 16-21.

Kim, J.W., Hao, J. and Lee, K.W. (2001). “New Attachment Device for Post-tensioning of Full Size Scale Space Truss", The Eighth East Asia-Pacific Conference on Structural Engineering \& Construction (EASEC-8), Singapore. Paper No.: 1034.

Kim, J.W. and Hao, J.P. (2002). "Behaviour Characteristic of a Full-Size Scale Pyramidal Space Truss Unit", KSCE Journal of Civil Engineering, Vol 6, No 1, pp 33-38.

Kim, J.W., Kim, J.J. and Lee, J.W. (2002). “Form Finding and 
Experiments for Three Types of Space Trusses", Space Structures 5, London(UK), Vol 1, pp 711-720.

Kim, J.W. and Kim, J.J. (2003). "Shape Formation of Hypar Space Truss by Cable-Tensioning", International Conference on Textile Composites and Inflatable Structures (Structural Membranes 2003), Barcelona(Spain), pp 353- 358.

Kim, J.W., Kim, J.J., and Rhew, H.J. (2004). "Analysis and Experiment for Self-erected Hypar Space Truss", Proceedings of the Second International Conference on Structural Engineering, Mechanics and Computation, Cape Town (South Africa), pp 365-369.

Kim J.W., Kim T.S. and Lee Y.H. (2006). "Shape Formation of Space Structure with Ball Type Joint", Proceedings of the Joint International Conference on Computing and Decision Making in Civil and Building Engineering. Montreal (Canada), Paper No. IC-10.

Kim J.W., Lee Y.H. and Doh J.H. (2007). “Analysis and Test for Shaping Formation of Space Truss by means of Cable-tensioning", Proceedings of 6th International Conference Steel and Aluminium Structures, London, Vol 1, pp 371-378.

Kim, J.W. and Schmidt, L.C. (2000). "Test of Deployable Dome-Shaped Space Truss", International Conference on Computing in Civil and Building Engineering (ICCCBEVIII), ASCE, California(USA), 1, pp 66-73.
Koushky, A.L., Dehdashti, G. and Fiouz, A.(2007). “Nonlinear Analysis of Double-Layer Grids with Compositive Nodes under Symmetric and Unsymmetrical Gravity Loads", International Journal of Space Structures, Vol 22, No 2, pp 133-144.

Punniyakotty, N.M., Richard Liew, J.Y. and Shanmugam N.E. (2000). "Nonlinear Analysis of Self-Erecting Framework by Cable-Tensioning Technique", J. Structural Engineering, Vol 126, No 3, pp 361-370.

Ramm, E. and Mehlhorn, G. (1991). “On Shape Finding Methods and Ultimate Load Analyses of Reinforced Concrete Shells", Engre. Struct., Vol 13, No 2, pp 178-198. Schmidt, L.C., Li, H. and Chua, M. (1999). "Post-tensioned and Shaped Hexagonal Grid Dome: Test and Analysis", Journal of Structural Engineering, ASCE Vol 124, pp 696-703.

2012년 6월 4일 원고 접수

2012년 9월 12일 심사 완료

2012년 10월 25일 게재 확정 